\title{
Nutraceutical quality of Opuntia ficus-indica developed under micro tunnel conditions, applying vermicompost
}

\author{
Alejandro Moreno Reséndez ${ }^{11}$, Dalia Meza Córtes ${ }^{1}$, José Luis Reyes Carrillo ${ }^{17 *}$,

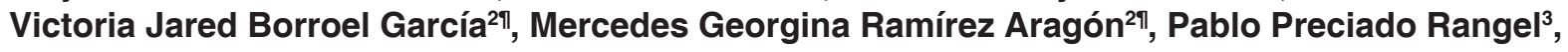 \\ Jolanta Elzbieta Marszalek ${ }^{4 \pi}$
}

\begin{abstract}
${ }^{1}$ Universidad Autónoma Agraria Antonio Narro, Periférico Raúl López Sánchez S/N. Colonia Valle Verde, Torreón, Coahuila, México, CP. 27054, 2Universidad Politécnica de Gómez Palacio. Carretera El Vergel - La Torreña, Km 0+820. El Vergel, CP 35120. Gómez Palacio, Dgo, ${ }^{3}$ Tecnológico Nacional de México, Instituto Tecnológico de Torreón, Carretera Torreón-San Pedro km 7.5, Ejido Ana, Torreón, Coahuila, CP 27170, ${ }^{4}$ Facultad de Ciencias Biológicas, Universidad Autónoma de Coahuila, Unidad Torreón, Ciudad Universitaria, Boulevard Matamoros s/n, San Ángel, Torreón, Coahuila, CP 27000

"Member of the Red Académica de Innovación en Alimentos y Agricultura Sustentable (RAIAAS) - sponsored by Consejo Estatal de Ciencia y Tecnología (COECYT) y La Comunidad de Instituciones de Educación Superior de la Laguna (CIESLAG)
\end{abstract}

\section{A B S T R A C T}

The demand for Opuntia spp., cladodes has increased substantially due to their low caloric value, high fiber content, their nutritional and functional characteristics and beneficial effects and phytochemical composition. The aim of this work was to determine the content of biochemical components and the antioxidant capacity of the nopal developed under micro tunnel conditions, with VC as a source of fertilization. The plants were grown under micro tunnel conditions with the manual vermicompost application at 15, 30 and $45 t^{\bullet} a^{-1}$. Between February and May 2019, four samplings of three cladodes (12 to $15 \mathrm{~cm}$ ) from each treatment were obtained. Samples were stored at $-20^{\circ} \mathrm{C}$ prior to obtaining ethanol extracts. Total phenolic content and total flavonoids were determined using a modification of Folin-Ciocalteu and Zhishen methods, respectively. The ABTS ${ }^{+}$test was performed with methodology proposed by Aubad-López. A split plot design, with two replicates, was used. The big plot corresponded to doses of vermicompost and subplots to the three varieties of nopal. Data were statistically analyzed by a two-way ANOVA with repeated measures. Statistical significance was obtained at $95 \%$ confidence level $(\alpha=0.05)$ using SPSS Statistics. The values recorded for the contents of total phenols, total flavonoids and the antioxidant activity, in the Chicomostoc, Chapingo and Narro varieties suggest that cladodes may be a promising source of natural antioxidants.

Keywords: Antioxidant activity; Cladodes; Phytochemical compounds; Organic fertilizer

\section{INTRODUCTION}

Every day, consumers are more focus on finding new products. Global trends in food production indicate a growing consumer attention to functional foods that provide extra benefits, in addition to their nutritional value (Gutiérrez-Pérez et al., 2013). Additionally, many consumers are interested not only in the commercial quality of horticultural products but also in their nutraceutical benefits, that is to say, their functional properties that can improve consumer's physical and mental state (TorresPonce et al., 2015; López-Martínez et al., 2016).

Most plant products are themselves considered functional foods for their high content of bioactive compounds such as vitamin $\mathrm{C}$, phenolic compounds, or carotenoids among others. Specifically, plant products that have antioxidant activity find application in the food, cosmetic and medicinal industries (de Ancos et al., 2016). Antioxidant have the ability to stop or delay oxidative cell processes, thus prevent damage to cells and the preservation of various cell functions. These characteristics present various plant and fruits as health-protective agents, which in turn relate to the prevention of chronic degenerative diseases such as cardiovascular diseases, different types of cancer and neurological problems (Rochín-Wong et al., 2013).

There is increasing evidence that fruits and vegetables may protect against numerous diseases. Their protective effect has generally been attributed to their antioxidant

\footnotetext{
${ }^{*}$ Corresponding author:

José Luis Reyes Carrillo, Universidad Autónoma Agraria Antonio Narro, Periférico Raúl López Sánchez S/N. Colonia Valle Verde, Torreón, Coahuila, México, CP. 27054. E-mail: jlreyes54@yahoo.com.mx
}

Received: 24 December 2020;

Accepted: 21 October 2020 
constituents, phenolic compounds (Bargougui et al., 2019). Polyphenols are chemical compounds of the secondary plant metabolism that can accumulate in specific group of plant organs such as leaves, fruits, roots, and stems (Karak, 2019). Flavonoids are secondary metabolic compounds, universally distributed in green plant kingdom (Samanta et al., 2011) and they are phenolic substances widely distributed in all vascular plants (Karak, 2019). The antioxidant activity of flavonoids results from a combination of their iron-chelating and free radical scavenging properties, in addition to the inhibition of oxidases; thus avoiding the formation of reactive oxygen species and organic hydroxyperoxides (Escamilla-Jiménez et al., 2009). Bargougui et al. (2019) highlight that the antioxidant activity of $O$. ficus-indica cultivars relates predominantly to the presence of phenolic compounds. Antioxidants compounds may help to reduce the oxidative stress, or delay oxidative processes, preventing free radicals from damaging biomolecules such as DNA, lipids, and proteins (Rochín-Wong et al., 2013). Additionally, it is widely known that the phenolic content of plant materials is strongly correlated with their antioxidant activity (Skerget et al., 2005; Astello-García et al., 2015), this is due to their redox properties, which present a key function in neutralizing free radicals (Dib et al., 2013).

In recent decades the importance of the use of organic fertilizers $(\mathrm{OF})$ has been reestablishing. Some reasons for that are found in the environmental impact of synthetic fertilizers, the increasing cost of synthetic fertilizers, and the need to preserve organic matter in agricultural systems. Organic matter is an essential component supporting the sustainability and productivity of natural agriculture (Fortis-Hernández et al., 2012). The practices of organic fertilization include the application of compost and/or vermicompost (VC), the increase of the organic matter of the soil, the support of the microbial activity, and gradual release of nutritive elements into the soil where they are easily available for plants allowing more balanced nutrition (Márquez-Quiroz et al., 2012). Vázquez-Vázquez et al. (2015), reported the effect of OFs on the photochemical quality of crops. They determined that the use of different OF namely compost, VC and solarized manure in the cultivation of Ocimum basilicum L., developed under shade house conditions, favored a higher phenolic content and higher antioxidant capacity.

Mexico is the main producer of prickly pear cactus worldwide and there are 104 varieties in this country (Sandoval-Trujillo et al., 2018). The genus Opuntia has almost 300 species, of which only 12 are used for human consumption (Galicia-Villanueva et al., 2017). The fruit is eaten fresh or used for the preparation of jellies and candies, while young cladodes are used in Mexican kitchen in a variety of dishes known under the name of "nopalitos". Over the years, this crop has gained extraordinary relevance because it has been incorporated into an everyday diet (Flores-Mendiola et al., 2012). Nopalitos are young and succulent cladodes from Opuntia and Nopalea genus consumed as vegetables (Maki-Díaz et al., 2018). The demand for nopalitos (Opuntia spp. cladodes) internationally and in Mexico has increased substantially due to their low caloric value, high fiber content, nutritional and functional characteristics (Sandoval-Trujillo et al., 2018) and their beneficial effects and phytochemical composition (Chahdoura et al., 2014). It has been reported that Opuntia cladodes are a good source of dietary fiber, which can help reduction in body weight by binding to dietary fat and increasing its elimination; this could be the reason why cladodes are considered hypolipidemic (Astello-García et al., 2015). Additionally, Torres-Ponce et al. (2015) emphasize that this plant species can be classified as a functional food, because of their qualities nutraceutical qualities such as the containment of dietary fiber and pectin, antioxidant, antiviral, anticancer, and anti-cholesterolemic activity, and the use in traditional medicine for diabetes control.

In México nopal is cultivated in two planting systems: the traditional, with densities ranging from 15,000 to 40.000 plants $\bullet \mathrm{h}^{-1}$, and the micro tunnels system, with densities from 120,000 to 160,000 plants $\bullet a^{-1}$ : the second system is used in regions with cold climates or during the winter production (Galicia-Villanueva et al., 2017). Orona-Castillo et al. (2003) highlight that given the climatic conditions prevailing in the Comarca Lagunera, the production of this crop can be carried out using micro tunnels in the coldest months December - February. The employment of these structures seeks to mitigate any effect of the presence of hail and frost (Maki-Díaz et al., 2018). In view of the elements described and considering the assumption that the application of VC could increase the nutritional quality of plants, the aim of this work was to determine the content of biochemical components and the antioxidant capacity of the nopal developed under micro tunnel conditions, with VC as a source of fertilization.

\section{MATERIALS AND METHODS}

\section{Experimental conditions}

The experimental work was carried out within a semicircular micro tunnel, of $30 \times 3.60 \mathrm{~m}$, length and width, respectively; covered with transparent plastic, 720 gauges. This structure was installed at Universidad Autónoma Agraria Antonio Narro - Unidad Laguna", in Torreón, Coabuila de Zaragoza, México $\left(101^{\circ} 40^{\prime}\right.$ and $104^{\circ} 45^{\prime} \mathrm{W}$ and $25^{\circ} 05^{\prime}$ and $26^{\circ} 54^{\prime} \mathrm{N}$ ) (Schmidt, 1989). Inside of the micro tunnel, Opuntia cactus plants of three varieties Chicomostoc (V1), Chapingo (V2), and 
Narro (V3) - were planted on 3 September 2017, applying $40 \mathrm{t} \cdot \mathrm{ha}^{-1}$ of bovine manure, on six plots of $9 \times 1.10 \mathrm{~m}$. Within each plot, 10 lines of each variety were planted with four cladodes per line (subplots) separated by $0.25 \mathrm{~m}$ and corresponding to a density of 121,212 plants $\bullet \mathrm{ha}^{-1}$. They were left to grow undisturbed for fifteen months.

To determine the effect of the VC on the nutraceutical quality of the nopal, on December 3, 2018, the amounts corresponding to three doses of VC $\left(15,30\right.$ and $\left.45 \mathrm{t}^{\bullet} \mathrm{ha}^{-1}\right)$ were manually applied to each big plot. The VC was prepared using three dungs of: horse, rabbit and goat - last mixed with alfalfa residues (Medicago sativa L.) - in a ratio 1:1:1 by volume, and exposed to earthworms Eisenia fetida Savigny for 90 days. The chemicals characteristics of VC are presented in Table 1.

During the period February - May 2019, approximately every 30 days, four samplings were carried out, in each of them three cladodes were obtained from the central part of each small plot, for a total of 54 cladodes per sample. The harvest of young cladodes was made when these reached a length between 12 and $15 \mathrm{~cm}$. They were washed in tap water for $2 \mathrm{~min}$ to remove residues and excess water was removed. The samples were placed in plastic bags, properly labeled, and transported in portable cooler at $10^{\circ} \mathrm{C}$, and stored at $-20^{\circ} \mathrm{C}$, in an ultra-freezer (Thermo Scientific serie $900 \circledR)$, to avoid degradation of secondary metabolites, until obtain the extracts.

\section{Extract preparation}

After defrosting, $1 \mathrm{~g}$ of plant material was weighed, placed in a test tube with a screw cap, and covered with $10 \mathrm{~mL}$ of absolute ethanol. The tubes were placed in a circular rotary shaker (Scientific ${ }^{\circledR}$ ) at $20^{\circ} \mathrm{C}$ for $12 \mathrm{~h}$ and at 20 rpm. Subsequently, the tubes were centrifuged at 3000 rpm for $5 \mathrm{~min}$, and supernatants were extracted for the corresponding analysis.

\section{Determination of total phenolics}

Total phenolic content was determined using a modification of Folin-Ciocalteu method (Singleton et al., 1999). This modification consisted of: $50 \mu \mathrm{L}$ of extract were mixed with $3 \mathrm{~mL}$ of distilled water in a test tube. Next, $250 \mu \mathrm{L}$ of Folin-Ciocalteu reagent (Sigma-Aldrich, St. Louis MO, USA) were added, vortexed for $10 \mathrm{~s}$, and left stirring for 3 minutes. After that time $750 \mu \mathrm{L}$ of sodium carbonate $[20 \%(\mathrm{w} / \mathrm{v})]$ were added and stirred for $10 \mathrm{~s}$. Subsequently, $950 \mu \mathrm{L}$ of distilled water was added, vortexed, and allowed to react for 2 hours at room temperature and in a dark place. The absorbance of the solution was read at $765 \mathrm{~nm}$ on a Genesys 10 UV spectrophotometer ${ }^{\circledR}$. Phenolic content was determined based on a calibration curve prepared using gallic acid as standard, and the results were reported in milligrams of gallic acid equivalent per $1 \mathrm{~g}$ of fresh weight $\left(\mathrm{mg} \mathrm{GAE} \cdot \mathrm{g}^{-1} \mathrm{FW}\right)$. Analyses were performed in triplicate.

\section{Determination of total flavonoids}

Total flavonoids were determined by the method developed by Zhishen et al. (1999), applying the following modifications, an aliquot of $250 \mu \mathrm{L}$ of the extract of each sample was mixed with $1000 \mu \mathrm{L}$ of deionized water, immediately afterwards, $75 \mu \mathrm{L}$ of $\mathrm{NaNO}_{2}$ were added and the solution was allowed to react $5 \mathrm{~min}$. Subsequently, $150 \mu \mathrm{L}$ of $\mathrm{AlCl}_{3}$ $(10 \%)$ and $500 \mu \mathrm{L}$ of $\mathrm{NaOH} 1 \mathrm{M}$ were added. The mixture was centrifuged at $3500 \mathrm{rpm}$ for $5 \mathrm{~min}$. The absorbance was measured at $510 \mathrm{~nm}$ by spectrophotometry (Genesys 10 UV spectrophotometer ${ }^{\circledR}$ ), and the results were reported in milligrams of total flavonoids based on quercetin (used as standard flavonoid for the calibration curve) per $1 \mathrm{~g}$ of fresh nopalito (mg QE $\mathrm{g}^{-1} \mathrm{FW}$ ). The analyses were performed in triplicate. The quercetin used as the standard was of the company: Sigma-Aldrich $95 \%$ (HPLC), solid CAS number 117-39-5.

\section{Determination of antioxidant activity}

The $\mathrm{ABTS}^{+}$test was performed according to the methodology proposed by Aubad-López et al. (2007). Applying the following modifications, the radical is generated by an oxidation reaction of 2, 2'-azinobis(3-ethylbenzothiazoline-6-sulfonic acid) [ABTS, (Sigma Aldrich, USA.)], with potassium persulfate. In the evaluation, $20 \mu \mathrm{L}$ of sample and $980 \mu \mathrm{L}$ of the $\mathrm{ABTS}^{+}$ solution in phosphate buffer were used, $\mathrm{pH}$ of 7.4. After 30 minutes the absorbance was recorded at $743 \mathrm{~nm}$ by spectrophotometry (Genesys 10 UV spectrophotometer ${ }^{\mathbb{R}}$ ). The calibration curve was performed using Trolox as standard and the results were expressed as total antioxidant capacity in Trolox micromols equivalents per $100 \mathrm{~g}$ of sample (TEAC $\mu \mathrm{m} \bullet 100 \mathrm{~g}^{-1} \mathrm{FW}$ ). Analyses were performed in triplicate. Fig. 1 shows the activities described in the previous paragraphs.

\section{Statistical analysis}

A split plot design, with two replicates, was used. The big plot corresponded to doses of VC $\left(15,30\right.$ and $\left.45 \mathrm{t} \bullet \mathrm{ha}^{-1}\right)$ and subplots to the three varieties of nopal [Chicomostoc (V1), Chapingo (V2) and Narro (V3)]. The variables evaluated

Table 1: Chemical analysis of the vermicompost used during development of nopal under micro tunnel conditions

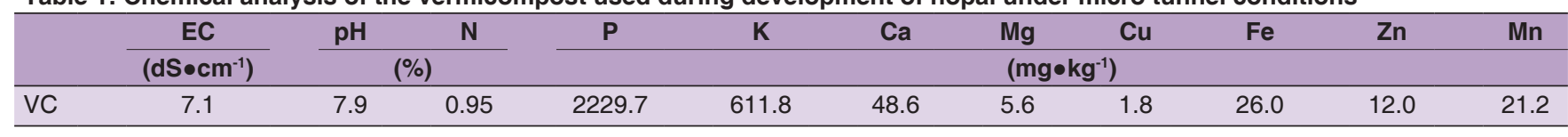




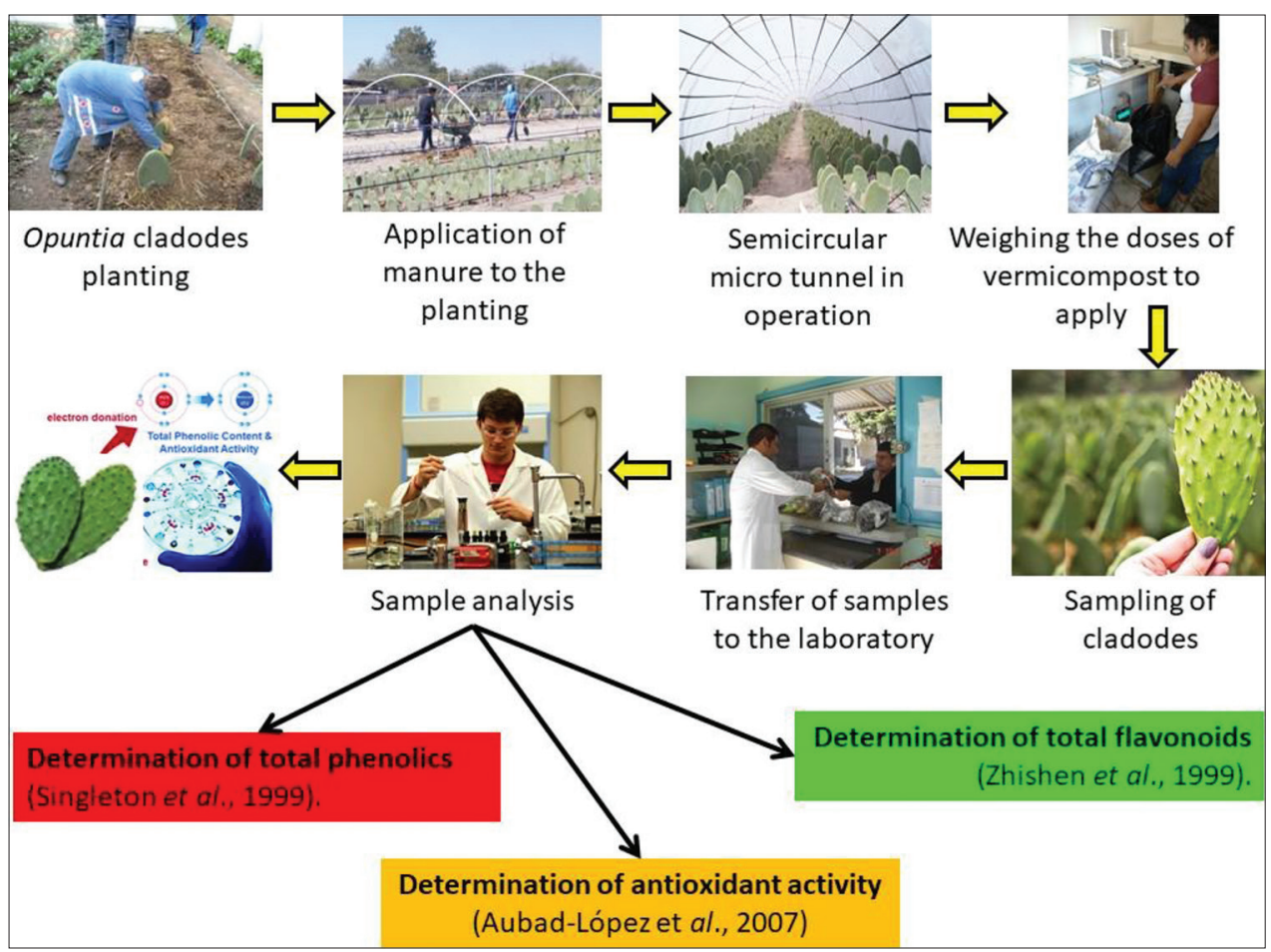

Fig 1. Diagram of the activities carried out in the experiment to determine nutraceutical quality of Opuntia ficus-indica developed under micro tunnel conditions applying vermicompost

were: total phenols, total flavonoids and antioxidant activity. Data were statistically analyzed by a two-way ANOVA with repeated measures. Statistical significance was obtained at $95 \%$ confidence level $(\alpha=0.05)$. Analyses were performed using the SPSS v. 25.0 (SPSS, 2017).

\section{RESULTS AND DISCUSSION}

Total phenolics, total flavonoids and antioxidant activity of prickly pear cactus cladodes were analyzed with respect to applying VC. These parameters measured in four samplings presented a normal distribution. The results of two-way ANOVA with repeated measures indicate that no statistical differences $(\mathrm{P} \leq 0.05)$ were registered for any of the variables under study, due to the effect of the dose of $\mathrm{VC}$ applied (Factor A), or to the varieties of nopal (Factor B), or to the interaction of these factors. Similarly Kapoulas et al. (2017) were not able to establish significant differences in nutrition values and qualities in their studied crops (lettuce and green onion). Figs. $2 \mathrm{a}$ and $2 \mathrm{~b}$ presents mean values finals of variables evaluated during the development of three varieties of nopal applying VC under micro tunnel conditions. Regardless of the recorded values for the variables under study, all samples of prickly pear cactus cladodes showed total phenols, total flavonoids, and antioxidant activity. This has been established as reported by Fonseca-García et al. (2014) and Santos-Díaz et al. (2017). The range of values for the total phenolics and total flavonoids contents, and for the antioxidant activity recorded was 1.56 to $3.10 \mathrm{mg} \mathrm{GAE}^{-1} \mathrm{FW}, 5.19$ to 8.43 mg QE $\bullet \mathrm{g}^{-1} \mathrm{FW}$ and 4,142.5 to 6,692.5 TEAC $\mu \mathrm{m} \bullet 100 \mathrm{~g}^{-1}$ FW, respectively. Generally, the levels of these functional groups are in accordance with previously reported values (Astello-García et al., 2015). The presence of phenolic compounds in crops is related to the protection of plants from pests and diseases (Ibrahim et al., 2012).

\section{Total phenolics in nopal}

Today it is widely known that the phenolic content of plant materials is strongly correlated with their antioxidant activity (Skerget et al., 2005; Astello-García et al., 2015), this is due to their redox properties, which present a key function in neutralizing free radicals (Dib et al., 2013). The range of values recorded, 1.56 to $3.10 \mathrm{mg} \mathrm{GAE} \cdot \mathrm{g}^{-1} \mathrm{FW}$ for the total phenolics, far exceeded the range of values of 0.04 to $0.27 \mathrm{mg} \mathrm{GAE} \cdot \mathrm{g}^{-1}$ determined by du Toit et al. (2018) in fresh cladodes of Robusta and Gymno Carpo cultivars. The range of total phenolic compound content in varieties evaluated was quite variable and according with Santos-Díaz et al. (2017) it may be due to the maturity stage, harvest season, environmental conditions, cultivars and postharvest treatment of crops. The lowest recorded value in this experiment, $1.56 \mathrm{mg} \mathrm{GAE} \cdot \mathrm{g}^{-1} \mathrm{FW}$, was determined for cladodes of nopal from Chicomostoc variety treated with $15 \mathrm{t} \bullet \mathrm{ha}^{-1}$ of VC. This value was slightly similar to the values of 2.07 and $1.05 \mathrm{mg} \mathrm{GAE} \cdot \mathrm{g}^{-1} \mathrm{FW}$ determined by Osorio- 


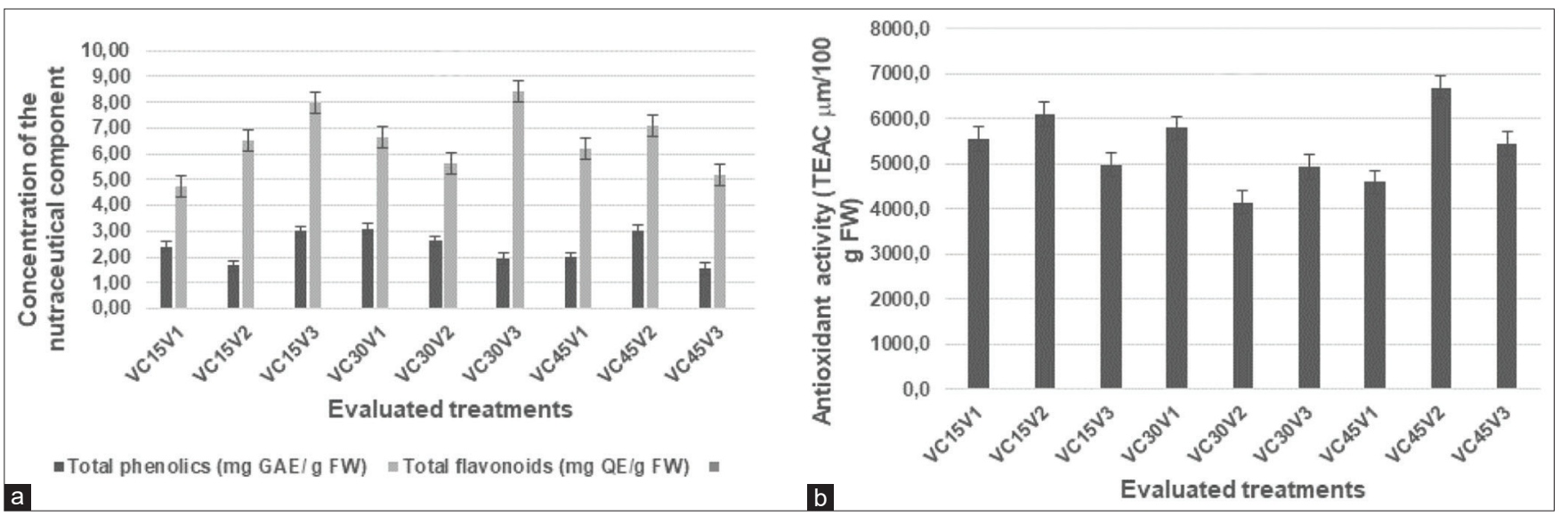

Fig 2. Mean values and standard deviation of total phenolics and flavonoids (a) and antioxidant activity (b) during the development of three varieties of nopal [Chicomostoc (V1), Chapingo (V2) and Narro (V3)] applying vermicompost (VC) under micro tunnel conditions. 15, 30 and $45=$ doses of VC applied $\left.\left(t^{\bullet}{ }^{-1}\right)^{-1}\right) ; F W=$ Fresh Weight.

Esquivel et al. (2011) in the pericarp of O. joconostle frutis and Mabrouki et al. (2015) in fruits pulp of O. ficus-indica, respectively. For its part, Rocchetti et al. (2018) reported total phenolic content in the extract of cladodes of $O$. ficusindica with levels slightly higher than those reported in this experiment, namely $2.63 \mathrm{mg} \mathrm{GAE} \cdot \mathrm{g}^{-1} \mathrm{FW}$.

The highest amount of total phenolic compounds, $3.10 \mathrm{mg} \mathrm{GAE} \cdot \mathrm{g}^{-1} \mathrm{FW}$, was found when applying 30 t• ha ${ }^{-1}$, in Narro variety. Dib et al. (2013) registered a much higher value of $26.7 \mathrm{mg} \mathrm{GAE} \cdot \mathrm{g}^{-1} \mathrm{DW}$ in dry samples of O. ficus-indica cladodes. The higher content of total phenolic compounds is due to the fact that drying of the samples causes a significant increase in the total flavonoids and phenolics, as well as, the antioxidant activity of plants (Roshanak et al., 2016). In other studies, phenolic values were reported to decrease during drying (du Toit et al., 2018). On the other hand, de Santiago et al. (2018) emphasize that the effect of cooking on different vegetables have shown that polyphenols are higher or lower in fresh food, depending on the vegetable and cooking method applied. In the experiment developed by Mardani-Talaee et al. (2015) they reported highest contents of anthocyanin and phenolic compounds when the use of VC was major (30\%). VC is produced by the activity of earthworms which is rich in macro and micronutrients, vitamins, growth hormones, enzymes such as proteases, amylases, lipase, cellulase and chitinase and immobilized microflora (Olle, 2019). Plants make use of the compounds originated by $\mathrm{CV}$ in order to generated phenolic compounds which are produced in the shikimic acid of plants and pentose phosphate through phenylpropanoid metabolization (Lin et al., 2016).

\section{Total flavonoids in nopal}

Flavonoids are secondary metabolic compounds, universally distributed in green plant kingdom. Of all these flavonoids compounds, quercetin is the most abundant, representing $60-75 \%$ of the total flavanols, the beneficial properties are closely related to its chemical structure, which gives it antioxidant properties (VicenteVicente et al., 2013). The use of quercetin as a standard for the determination of flavonoids is due to its chelating properties and the ability to trap free radicals, this allows to establish the existence of the compounds of interest (Pérez-Trueba, 2003).

Flavonoids protects plants from different biotic and abiotic stresses and act as unique UV-filter. They function as signal molecules, allelopathic compounds, phytoalexins, detoxifying agents, antimicrobial defensive compounds and have roles against frost hardiness, drought resistance and maybe even plant heat acclimation and freeze tolerance (Samanta et al., 2011). The antioxidant activity of flavonoids results from a combination of their ironchelating and free radical scavenging properties, in addition to the inhibition of oxidases; thus avoiding the formation of reactive oxygen species and organic hydroxyperoxides (Escamilla-Jiménez et al., 2009).

The highest amount of total flavonoids, $8.43 \mathrm{mg}$ QE $\mathrm{g}^{-1}$ FW, was found in Narro variety when applying $30 \mathrm{t} \bullet \mathrm{ha}^{-1}$ of VC. This value was widely surpassed the content of 0.46 $\mathrm{mg}$ QE $\mathrm{g}^{-1} \mathrm{FW}$ of total flavonoids, reported by OsorioEsquivel et al. (2011) in the pericarp of O. joconostle fruits. It also was much higher than reported by Bargougui et al. (2019) for methanol extracts of four O. ficus-indica cultivars. They determined flavonoid levels of $0.26,0.30,0.31$, and $0.34 \mathrm{mg} \mathrm{QE} \mathrm{g}^{-1} \mathrm{FW}$ for Ain Amara (Tunisia), Lengissima (Algeria), Ain Jemaa (Moraco), and Sanguinea (Italy) varieties, respectively. On another hand, the highest value of total flavonoids registered in the present experiment was slightly exceeded by the value of $11.86 \mathrm{mg} \mathrm{QE} \mathrm{g}^{-1} \mathrm{DW}$, determined by Dib et al. (2013) in dry samples of cladodes of O. ficus- 
indica, which again could be overestimated due the drying process (Roshanak et al., 2016). It is worth mentioning that VC stimulates mycorrhizal colonization of the roots and due to it VC could induce nutritional stress by increasing the phenolic content. Studies have also reported that P, B, and $\mathrm{Mn}$ deficiency induces flavonoid accumulation, while $\mathrm{Co}$ and Ni supplementation increases flavonoid production and antioxidant enzyme activity (Lujan-Hidalgo et al., 2015).

\section{Antioxidant activity of the nopal}

Bargougui et al. (2019) highlight that the antioxidant activity of $O$. ficus-indica cultivars relates predominantly to the presence of phenolic compounds, as these are the major contributors in the prevention process. The antioxidant activity of phenolic compounds is mainly due to their redox properties, which can play an important role in absorbing and neutralizing free radicals, quenching singlet and triplet oxygen, or decomposing peroxides (Dib et al., 2013). Antioxidants compounds may help to reduce the oxidative stress, or delay oxidative processes, preventing free radicals from damaging biomolecules such as DNA, lipids, and proteins (Rochín-Wong et al., 2013).

The highest amount of antioxidant activity, 6,692.5 TEAC $\mu \mathrm{m} \bullet 100 \mathrm{~g}^{-1} \mathrm{FW}$, was registered when applying VC in doses

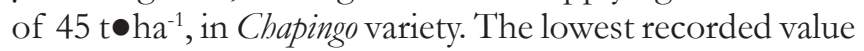
of antioxidant activity in cladodes was $4,142.5 \mu \mathrm{m}$ TEAC• $100 \mathrm{~g}^{-1} \mathrm{FW}$ registered for the same variety under the doses of $30 \mathrm{t} \mathrm{ha}^{-1}$ of VC. Controversial results were detected for antioxidant activity in cladodes of Opuntia spp. Some values were much lower, $11.26 \mu \mathrm{m}$ TEAC $100 \mathrm{~g}^{-1} \mathrm{FW}$ (de Santiago et al., 2018) and some were much higher, close to $63,000 \mu \mathrm{m} \mathrm{TEAC} \cdot 100 \mathrm{~g}^{-1} \mathrm{DW}$ (Astello-García et al., 2015). Astello-García et al. (2015) analyzed extracts of dry cladodes samples of Opuntia spp: O. streptacantha, O. byptiacantha, O. megacantha, O. albicarpa, and O. ficus-indica, and measured the antioxidant activity at average values of $62,980,36,850,60,250,40,620$ and $50,840 \mu \mathrm{m}$ TEAC $100 \mathrm{~g}^{-1} \mathrm{DW}$, respectively. The drying of the samples causes significant increase of antioxidant activity of plants (Roshanak et al., 2016).

\section{Effect of vermicompost}

Although the dimensions of the micro tunnel did not permit to include a control with conventional fertilization, the results obtained allow to assume according to Omar et al. (2012) that the application of VC can enhance the contents of total phenols, total flavonoids and the antioxidant activity of three varieties of nopal; also were determined that the total flavonoids and phenolics content of VC treated plants were 39 and $38 \%$ higher, respectively than those treated with conventional fertilizer. The antioxidant activity determined using the 1,1-Diphenyl-2picryl-hydrazyl (DPPH) and Ferric Reducing Antioxidant
Power (FRAP) assays were high with application of organic fertilizer. Another reason for high concentrations of phenolic compounds in organically grown crops is the absence of pesticide residues in their organ/tissues which have been found to decrease the phenolic contents (Kapoulas et al., 2017).

The elevation of polyphenols and flavonoids in nopalitos registered in the present experiment, in part, could have been due to the following aspects: the application and mineralization of organic matter participates in important metabolic processes in plant nutrition, specifically ureases and phosphatases, these act directly in biogeochemical cycles, promoting the increase of bioactive compounds such as phenolics and flavonoids (Álvarez-Solís et al., 2010). Furthermore, VC is a slow releasing nutrient source providing nutrients in synchrony with plant needs, and its application can increase the production of phenolic compounds in plants (Domínguez et al., 2010).

\section{CONCLUSION}

Although the doses of $\mathrm{VC}$ applied did not generate statistical differences on the content of the biochemical components or on the antioxidant capacity of the nopal varieties, developed under micro tunnel conditions, the values recorded for the contents of total phenols, total flavonoids and the antioxidant activity in the Chicomostoc, Chapingo and Narro varieties suggest that their cladodes might be a promising source of natural antioxidants.

\section{ACKNOWLEDGEMENTS}

This research was supported by a grant of the Universidad Autónoma Agraria Antonio Narro, with the code 38-1114256001002-2447. Engineer Eliseo Raygoza Sánchez is thanked for the support given throughout the experiment.

\section{Author contributions}

"Conceptualization, Alejandro Moreno Reséndez and José Luis Reyes Carrillo; Methodology, Victoria Jared Borroel García and Mercedes Georgina Ramírez Aragón; Formal Analysis, Victoria Jared Borroel García, Jolanta Elzbieta Marszalek and Mercedes Georgina Ramírez Aragón; Investigation, Alejandro Moreno Reséndez, Pablo Preciado Rangel and Dalia Meza Córtes; Resources, Alejandro Moreno Reséndez and José Luis Reyes Carrillo; Writing Original Draft Preparation, Alejandro Moreno Reséndez and Dalia Meza Córtes; Writing - Review \& Editing, José Luis Reyes Carrillo, Pablo Preciado Rangel and Jolanta Elzbieta Marszalek; Project Administration, Alejandro Moreno Reséndez; Funding Acquisition, Alejandro Moreno Reséndez and José Luis Reyes Carrillo" 


\section{REFERENCES}

Álvarez-Solís, J. D., D. A. Gómez-Velasco, N. S. León-Martínez and F. A. Gutiérrez-Miceli. 2010. Integrated management of inorganic and organic fertilizers in maize cropping. Agrociencia. 44: 575-586.

Astello-García, M. G., I. Cervantes, V. Nair, M. Santos-Díaz, A. del S. Reyes-Agüero, F. Guéraud, A. Negre-Salvayre, M. Rossignol, L. Cisneros-Zevallos and A. P. Barba-de la Rosa. 2015. Chemical composition and phenolic compounds profile of cladodes from Opuntia spp. cultivars with different domestication gradient. J. Food Compos. Anal. 43: 119-130.

Aubad-López, P., B. A. Rojano and T. Lobo-Echeverri. 2007. Actividad antioxidante en musgos. Sci. Tech. 13: 23-26.

Bargougui, A., H. M. Tag, M. Bouaziz and S. Triki. 2019. Antimicrobial, antioxidant, total phenols and flavonoids content of four cactus (Opuntia ficus-indica) cultivars. Biomed. Pharmac. J. 12: 1353-1368.

Chahdoura, H., J. C. M., Barreira, L. Barros, C. Santos-Buelga, I. C. F. Ferreira and L. Achour. 2014. Phytochemical characterization and antioxidant activity of the cladodes of Opuntia macrorhiza (Engelm.) and Opuntia microdasys (Lehm.). Food Funct. 5: 2129-2136.

de Ancos, B., I. Fernández-Jalao and C. Sánchez-Moreno. 2016. Functional compounds in fresh-cut and ready-to-eat products. Rev. Iberoamer. Tecnol. Postcosecha. 17: 130-148.

de Santiago, E., M. Domínguez-Fernández, C. Cid and M. P. de Peña. 2018. Impact of cooking process on nutritional composition and antioxidants of cactus cladodes (Opuntia ficus-indica). Food Chem. 240: 1055-1062.

Dib, M. H., C. Beghdad, M. Belarbi, M. Seladji and M. Ghalem. 2013. Antioxidant activity of phenolic compounds of the cladodes of Opuntia ficus-indica mill. From Northwest Algeria. Int. J. Med. Pharm. Sci. 3: 147-158.

Domínguez, J., M. Gómez-Brandón and C. Lazcano. 2010. Biopesticide properties of vermicompost. Acta Zool. Mex. (n. s.). Número Especial. 2: 373-383.

du Toit, A., M. de Wit, G. Osthoff and A. Hugo. 2018. Antioxidant properties of fresh and processed cactus pear cladodes from selected Opuntia ficus-indica and O. robusta cultivars. S. Afr. J. Bot. 118: 44-51.

Escamilla-Jiménez, C. I., E. Y. Cuevas-Martínez and J. GuevaraFonseca. 2009. Flavonoides y sus acciones antioxidantes. Rev. Fac. Med. 52: 73-75.

Flores-Mendiola, G. R., H. Rodas-Gaitán, H. Rodríguez-Fuentes, J. A. Vidales-Contreras, E. Sánchez-Alejo and J. Aranda-Ruiz. 2012. Producción de biomasa seca y parámetros sensoriales de nopal verdura cultivado en forma hidropónica. Edición Especial. 175-190.

Fonseca-García, L., L. S. Calderón-Jaimes and M. E. Rivera. 2014. Antioxidant capacity and total phenol content in coffee and coffee by-products produced and marketed in Norte de Santander (Colombia). VITAE. 21: 228-236.

Fortis-Hernández, M., P. Preciado-Rangel, J. L. García-Hernández, A. Navarro-Bravo, J. Antonio-González and J. M. OmañaSilvestre. 2012. Organic substrates in the production of sweet pepper. REMEXCA. 3: 1203-12161.

Galicia-Villanueva, S., P. E. Escamilla-García, H. Alvarado-Raya, L. V. Aquino-González, H. Serna-Álvarez and L. M. HernándezCruz. 2017. Experimental plantation of nopal for evaluation of fertilization and mucilage extraction systems. REMEXCA. 8: 1087-1099.

Gutiérrez-Pérez, C., H. Morales and F. Limón-Aguirre. 2013. Opinions about the quality of organic food products, and the origin of the local consumer network "Comida Sana y Cercana" in Chiapas. Rev. Limina. Est. Soc. Human. 11: 104-117.

Ibrahim, M. H., H. Z. E. Jaafar, E. Karimi and A. Ghasemzadeh. 2012. Primary, secondary metabolites, photosynthetic capacity and antioxidant activity of the Malaysian herb kacip Fatimah (Labisia pumila Benth) exposed to potassium fertilization under greenhouse conditions. Int. J. Mol. Sci. 13: 15321-15342.

Kapoulas, N., A. Koukounaras and Z. S. Ilić. 2017. Nutritional quality of lettuce and onion as companion plants from organic and conventional production in north Greece. Sci. Hortic. 219: 310-318.

Karak, P. 2019. Biological activities of flavonoids: An overview. Int. J. Pharm. Sci. Res. 10: 1567-1574.

Lin, D., M. Xiao, J. Zhao, Z. Li, B. Xing, X. Li, M. Kong, L. Li, Q. Zhang, Y. Liu, H. Chen, W. Qin, H. Wu and S. Chen. 2016. An overview of plant phenolic compounds and their importance in human nutrition and management of Type 2 diabetes. Molecules. 21: 1374.

López-Martínez, J. D., D. A. Vázquez-Díaz, J. R. Esparza-Rivera, J. L. García-Hernández, M. A. Castruita-Segura and P. PreciadoRangel. 2016. Yield and nutraceutical quality of tomato fruit produced with nutrient solutions prepared using organic materials. Rev. Fitotec. Mex. 39: 409-414.

Luján-Hidalgo, M. C., L. E. Pérez-Gómez, M. Abud-Archila, R. Meza-Gordillo, V. M. Ruiz-Valdiviezo, L. Dendooven and F. A. Gutiérrez-Miceli. 2015. Growth, phenolic content and antioxidant activity in chincuya (Annona purpurea Moc and Sesse ex Dunal) cultivated with vermicompost and phosphate rock. Compost Sci. Util. 23: 276-283.

Mabrouki, L., B. Zougari, M. Bendhifi, M. A. Borgi. 2015. Evaluation of antioxidant capacity, phenol and flavonoid contents of Opuntia streptacantha and Opuntia ficus indica fruits pulp. NATEC. 13: $2-8$.

Maki-Díaz, G., C. B. Peña-Valdivia and M. L. Arevalo-Galarza. 2018. Trends in production, postharvest management and national and export commercialization of nopalito (Opuntia ficus-indica). Agro Prod. 11: 73-79.

Mardani-Talaee, M., A. Zibaee, G. Nouri-Ganbalani, V. Rahimi and P. Tajmiri. 2015. Effect of vermicompost on nutrition and intermediary metabolism of Colorado potato beetle, Leptinotarsa decemlineata (Say) (Coleoptera: Chrysomelidae). Arch. Phytopath. Plant Protect. 48: 623-645.

Márquez-Quiroz, C., P, Cano-Ríos, A. Moreno-Reséndez, E. SánchezChávez, E. de la Cruz-Lázaro, U. Figueroa-Viramontes and V. Robledo-Torres. 2014. Effect of organic fertilization on yield and nutrient content of saladette tomato in greenhouse. Inform. Tech. Econ. Agria. 110: 3-17.

Pérez-Trueba, G. 2003. Los flavonoides: antioxidantes o prooxidantes. Rev. Cubana Invest. Biomed. 22: 48-57.

Omar, N. F., S. A. Hassan, U. K. Yusoff, N. A. Psyquay-Abdullah, P. E. Megat-Wahab and U. Sinniah. 2012. Phenolics, flavonoids, antioxidant activity and cyanogenic glycosides of organic and mineral-base fertilized cassava tubers. Molecules. 17: 23782387.

Olle, M. 2019. Review: Vermicompost, its importance and benefit in agriculture. J. Agric. Sci. 2: 93-98.

Orona-Castillo, I., A. Flores-Hernández, M. Rivera-González, J. Guillermo-Martínez, J. J. Espinoza-Arellano. 2003. Water productivity in prickly pear using drip irrigation in the Lagunera Region. Terra Latinoam. 21: 195-201.

Osorio-Esquivel, O., A. Ortiz-Moreno, V. B. Alvarez, L. DorantesÁlvarez and M. Giusti. 2011. Phenolics, betacyanins and antioxidant activity in Opuntia joconostle fruits. Food Res. Int. 44: 2160-2168. 
Rocchetti, G., M. Pellizzoni, D. Montesano and L. Lucini. 2018. Italian Opuntia ficus-indica cladodes as rich source of bioactive compounds with health-promoting properties. Foods. 7: 1-12.

Rochín-Wong, C. S., N. Gómez-Meza, L. C. Montoya-Ballesteros and L. A. Medina-Juárez. 2013. Effect of drying and pickling processes on antioxidant capacity of phytochemicals of chiltepin (Capsicum annuum L. var. glabriusculum). Rev. Mex. Ing. Quím. 12: 227-239.

Roshanak, S., M. Rahimmalek and S. A. Hossein-Goli. 2016. Evaluation of seven different drying treatments in respect to total flavonoid, phenolic, Vitamin C content, chlorophyll, antioxidant activity and color of green tea (Camellia sinensis or C. assamica) leaves. J. Food Sci. Technol. 53: 721-729.

Samanta, A., G. Das, S. K. Das. 2011. Roles of flavonoids in plants. Int. J. Pharm. Sci. Tech. 6: 12-35.

Sandoval-Trujillo, S. J., V. Ramírez-Cortés and B. E. HernándezBonilla. 2018. Análisis de los incentivos para la producción del nopal en Teotihuacán. Vinculategica. 4: 382-290.

Santos-Díaz, M. S., A. P. Barba-de la Rosa, C. Héliès-Toussaint, F. Guéraud and A. Nègre-Salvayre. 2017. Opuntia spp.: Characterization and benefits in chronic diseases. Oxid. Med. Cell. Longev. 2017: 1-17.

Schmidt, R. H. Jr. 1989. The arid zones of Mexico: Climatic extremes and conceptualization of the Sonoran Desert. J. Arid Environ. 16: 241-256.
Singleton, V. L., R. Orthofer and R. M. Lamuela-Raventos. 1999. Analysis of total phenols and other oxidation substrates and antioxidants by means of Folin-Ciocalteu reagent. Methods Enzymol. 299: 152-178.

Skerget, M., P. Kotnik, M. Hadolin, A. Hras, M., Simonic and Z. Knez. 2005. Phenols, proanthocyanidins, flavones and flavonols in some plant materials and their antioxidant activities. Food Chem. 89: 191-198.

SPSS. 2017. IBM Corp. Released 2017. IBM SPSS Statistic for Windows, Version 25.0. IBM Corp, Armonk, NY.

Torres-Ponce, R. L., D. Morales-Corral, M. L. Ballinas-Casarrubias and G. V. Nevárez-Moorillón, 2015. Nopal: Semi-desert plant with applications in pharmaceuticals, food and animal nutrition. REMEXCA. 6: 1129-1142.

Vázquez-Vázquez, C., G. I. Ojeda-Mijares, M. Fortis-Hernández, P. Preciado-Rangel and J. Antonio-González. 2015. Organic substrates in the production of basil (Ocimum basilicum L.) and its phytochemical quality. REMEXCA. 6: 1833-1844.

Vicente-Vicente, L., M. Prieto and A. I. Morales. 2013. Efficacy and safety of quercetin as dietary supplement. Rev. Toxicol. 30: 171-181.

Zhishen, J., T. Mengcheng and W. Jianming. 1999. The determination of flavonoid contents in mulberry and their scavenging effects on superoxide radicals. Food Chem. 64: 555-559. 